\title{
Wielkie Nić / The Big Thread. Case Study
}

\section{Agnieszka Grygiel}

A la teatr Association, Poland

E-mail address: alateatr@gmail.com

ARTICLE INFO

\section{Keywords:}

Play

Handicraft

Common work

Creative process

Community creation

Article history:

Received 22 December 2016

Received in revised form 11 May 2017

Accepted 20 May 2017

ISSN: 2354-0036

DOI: 10.1515/ctra-2017-0008
A B S T R A C T

The aim of this case study is to describe the social project "Wielkie nić / The Big Thread" - the creation of embroidered messages - which has many features in common with children's play. Just like play, it needs space, time and rules, but at the same time, also a lot of freedom. And neither need spectators. Moreover, the project - like a form of symbolic play, where children use abstract things to represent reality has a metaphorical significance. The threads, used for common embroidery, truly connect people. They realize how much they have in common and how they need each other. This can give a sense of unity and community and even change their consciousness.

\section{INTRODUCTION}

The social project "Wielkie Nić / The Big Thread” is organized by the A la teatr Association created by Grygiel, Oses and Klimaszewski. The group believes that "creating together creates togetherness", and over the years they have been inviting the residents of Poznań to create embroidered messages on billboards. These were displayed at the largest exhibition venue in the world, that is on the streets, providing a platform for creative thinking and opportunities for instant community-creation. This kind of simple physical work is also an apotheosis of handiwork created at home, which now acquires a social dimension when it enters the streets.

The artists have realized the "The Big Thread" on several occasions, including the Malta Festival and the "Inwazja Barbarzyńców" (Invasion by Barbarians) Festival in Poznan, during the celebration of the 60th anniversary of the Poznan Workers' Uprising and the programme of "Lato w teatrze" (Summer in the Theatre) with The Theatre Institute - workshops for children in Mosina near Poznan. Additionally, the artists have used the author's method during numerous workshops with children. 


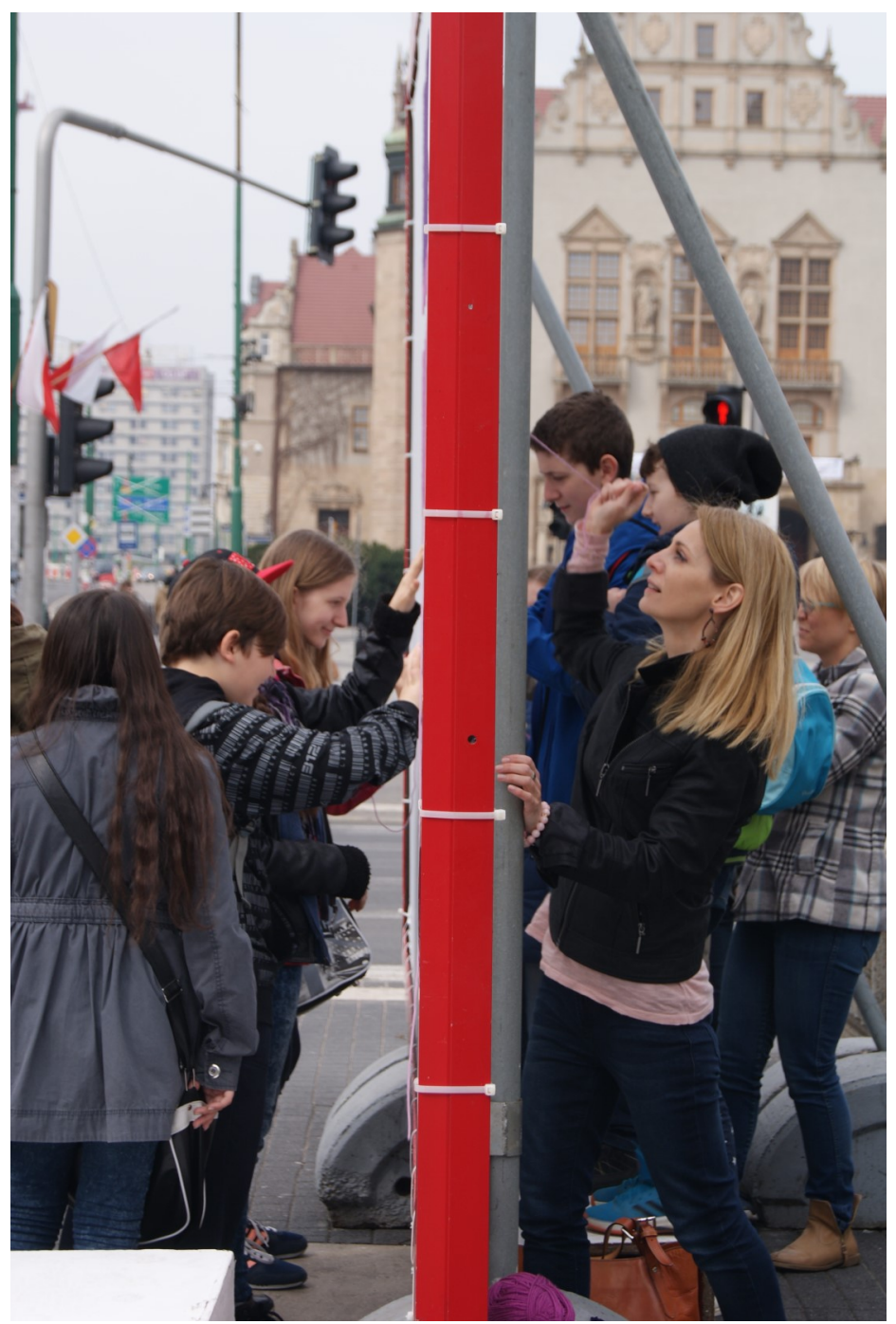

Figure 1. Participants pass each other a thread, standing on both sides of huge frame. (fot. A. Grygiel).

\section{PLAY WITH PEOPLE AND LETTERS - FOR THE FIRST TIME}

Our first experience with "Wielkie nić" took place in the early summer of 2013. On that day, 22nd June, all you dreamt about was some place in the shade, a glass of cold water and possibly a lot of ice cream. It was not the best kind of weather to create something outdoors, especially something as useless as embroidery. To be specific, it was embroidery on a large commercial billboard - $3 \mathrm{~m} \times 6 \mathrm{~m}$, placed in the middle of a sun-scorched square. When we arrived there, with a basket full of needles and wool, the place was almost completely empty and really hot, and it was $10 \mathrm{am}$. Finding the participants was a real challenge for us, people who were willing to spend even a few moments with us. But we were determined to make the project a success. So, we began walking around the square and asking people to join us. Slowly, with some scepticism, people started coming up to observe us and ask "why we were making it?" and "what it was?". They finally began to join us in embroidering. At about noon, we had about eight people involved in the process. What exactly we were making, were huge letters, half-a-metre 
high, which stood for the name of the inhabitants of the district where we were performing. The district is called Wilda, and the residents are called Wildzianie. We used that word WIL-DZIANIE intentionally as a sort of symbolic expression. The second part of the word is "DZIANIE" which means "happening" in Polish. The word "DZIANIE", however, also means "knitting".



Figure 2. Disabled people can also take part in embroiding. (fot. P. Będliński).

\section{NEW PLAY - NEW EXPERIENCE}

At about 12.30 p.m., two women with big baskets stopped next to us. They were on their way back from a shop. They stopped just for a while. They began working on the letter "D". They stayed more than an hour and seemed very proud when they had finished their part of the work. They expressed the opinion that they felt a part of this shared work. "I feel I am a part of it" - this is a very important feeling associated with our project. At about 3 a.m. a middle-aged couple came by with a dog and joined in. Their dog was very patient. Patience and quietness were also important feelings accompanying this project. The couple started doing the letter "N". They stayed maybe 1,5 hours then went back home to eat something and to leave the dog at home. After a while they returned to us to finish the letter. "We had to finish our task", they said with pride. This feeling was also very often expressed during our work. Obviously, children were with us too! They were amazing with their enthusiasm and energy. For them it was simply fun. Every action, such as cutting thread, beading, passing scissors to adults, was a reason to participate in the "big play activity". They did what is natural to them, they played. 




Figure 3. Here everybody is a creator. (fot. Maciej Zakrzewski).

\section{RULES OF PLAY - SPACE AND TIME}

What conditions did we have to set for adults to gear up their willingness to play, to have fun? Our main task was to create a playfield for people with different skills, experiences and social status. First of all, where we performed was very important. On the first occasion we embroidered on a square where the inhabitants had tried to create a small garden. We used the place because of its dimensions. It helped us to build intimacy. We experienced an evident difference between that place and Plac Wolności - a large and busy square in the centre of Poznań, where we embroidered later. In the first, smaller place, most of the people stayed with us longer, while in the second place, they just passed by and we heard more often that they were in a hurry. Compared to the central place, the "garden" on Wilda had a more local character. There, people were interested in what was going on and they had time to have a look at what we were trying to do, and to think about joining us. On the other hand, on Plac Wolności more people joined us, but they did so for a shorter time. During our preparations for the project, we also consciously chose the day of the event. Because on weekdays people are very busy, and probably fewer people would have been interested in joining us, we decided to organize the performance on a Saturday. This day, in the minds of the city's inhabitants, is considered as time of leisure and creative activities. 


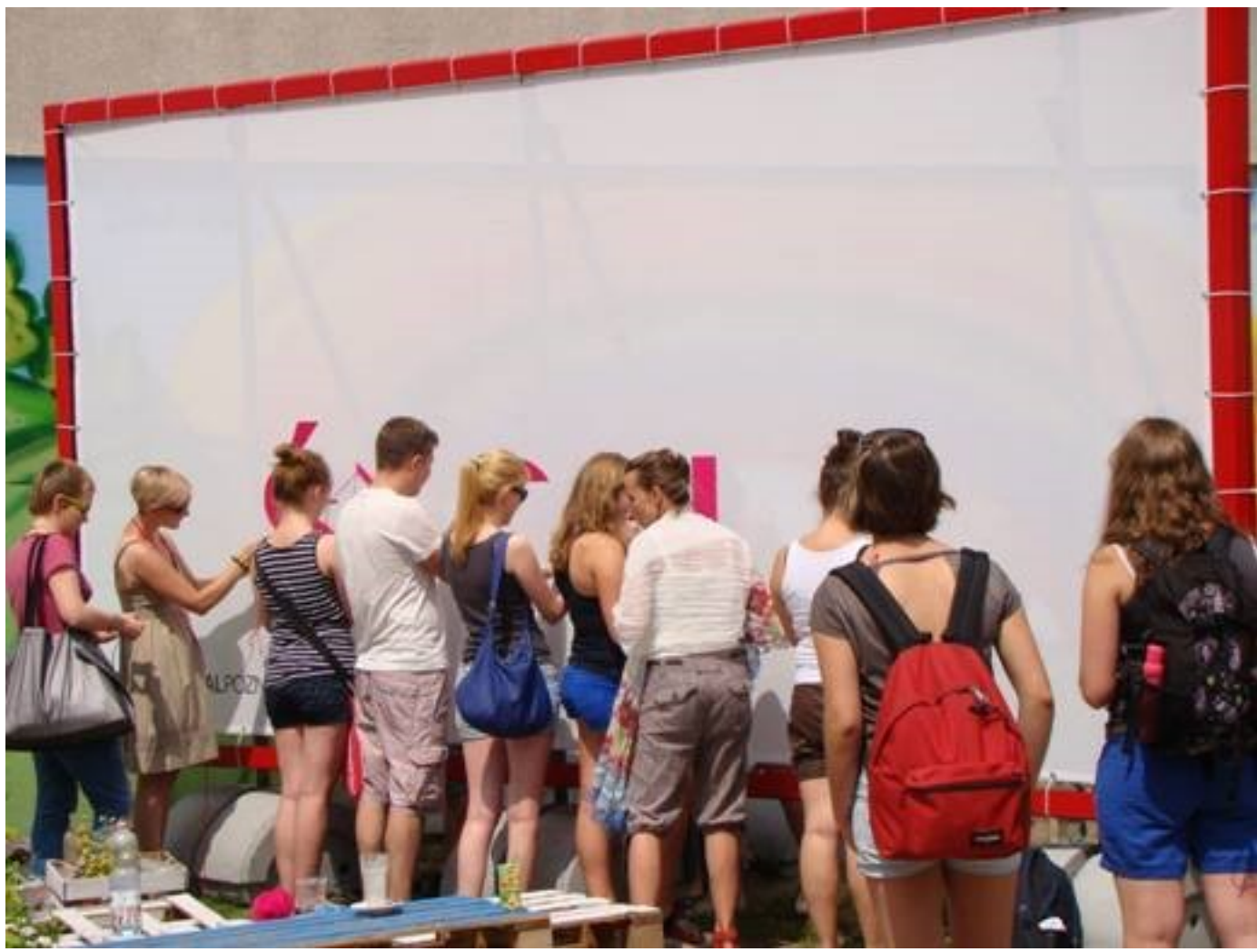

Figure 4. Even 20 person can work together in the same time. (fot. A. Grygiel).

\section{RULES OF PLAY - NO SPECTATORS}

So, what about the spectators in our project? Nothing special, because when someone stopped to observe, in a few minutes, that person was with us, embroidering. It seems to us that the desire to participate, to be a part of something, must be deeply rooted in people. There must be a strong need in people to create something together or, I would say, to create some togetherness. And it seemed that those who participated were so absorbed in the work that they did not even notice that somebody was watching them. In that moment it was only "me in performance", as is the case during children's play. So, if in play, there is no audience, neither is there any in our performance. Everybody is inside the common work. When I observe children playing, I have to be aware as a spectator. I can readily notice when they know that they are being observed. At that moment, and usually it is only a few minutes, they change their behavior. They know that they have an audience, and they do something for the audience. Fortunately for children it is only a short time. What about adults? Do we behave in the same way when we know we are being "tracked"? Could you work with full-time surveillance? 




Figure 5. Everyone can embroider regardless of age and and skill.

(fot. Maciej Zakrzewski).

\section{RULES OF PLAY - AM I CAPABLE ENOUGH?}

I would like to say a bit about the ability to embroider. The participants do not actually need any special skills. When we were preparing the project, we intentionally designed a way of performing that would be a challenge, but a small one. The participants need to feel that they can try without the riskof something wrong happening. It is the kind of challenge that you face when you say to yourself: "I have never done this before, but I feel that here, I can try". In "Wielkie nić" we have no teacher in the traditional sense. But because of our constant interaction with the participants, we create a situation of peer -to-peer learning. In that way, we have consciously built a safe space and atmosphere of trust. We tried to create a sense of intimacy. Every gesture is meant to say: "Take a chance. Just give it a try."



Figure 6. Full engagement is connected here with the relax and respite from everyday matters. (fot. A. Grygiel). 


\section{RULES OF PLAY - EMOTIONS}

Now, one may ask why we used this huge billboard, that is normally used for advertising. For a couple of reasons. Firstly, because of its dimensions, many people are able to work together. Secondly, the billboard is in an open public space available to anybody, so we can work with ordinary people. Thirdly, paradoxically some people feel hidden and safer when standing behind a huge net and exchanging needles and threads. There and back, there and back, minute by minute, hour by hour. We are certain there were moments when some people felt a kind of meditation, a relaxed state of mind. What is astonishing, at those moments, people felt encouraged to be in contact with others and to talk. But they did not feel the time passing. Afterwards, they were surprised how time had flown: "I stopped here for a while and I stayed one hour. So strange. What happened to me?". During the whole process, we observed a change in the participants' reactions. At the beginning, when we asked people to join us, we saw some fear: "I do not know how to embroider. I may spoil it". And by the end of their work they felt joy, pride and fulfilment. This small activity brought them relief, respite, pure joy, and the feeling of getting away "from it all". They even spoke about gaining a life-balance for a while. Some of them, when they had finished their letter, talked about the feeling of success.

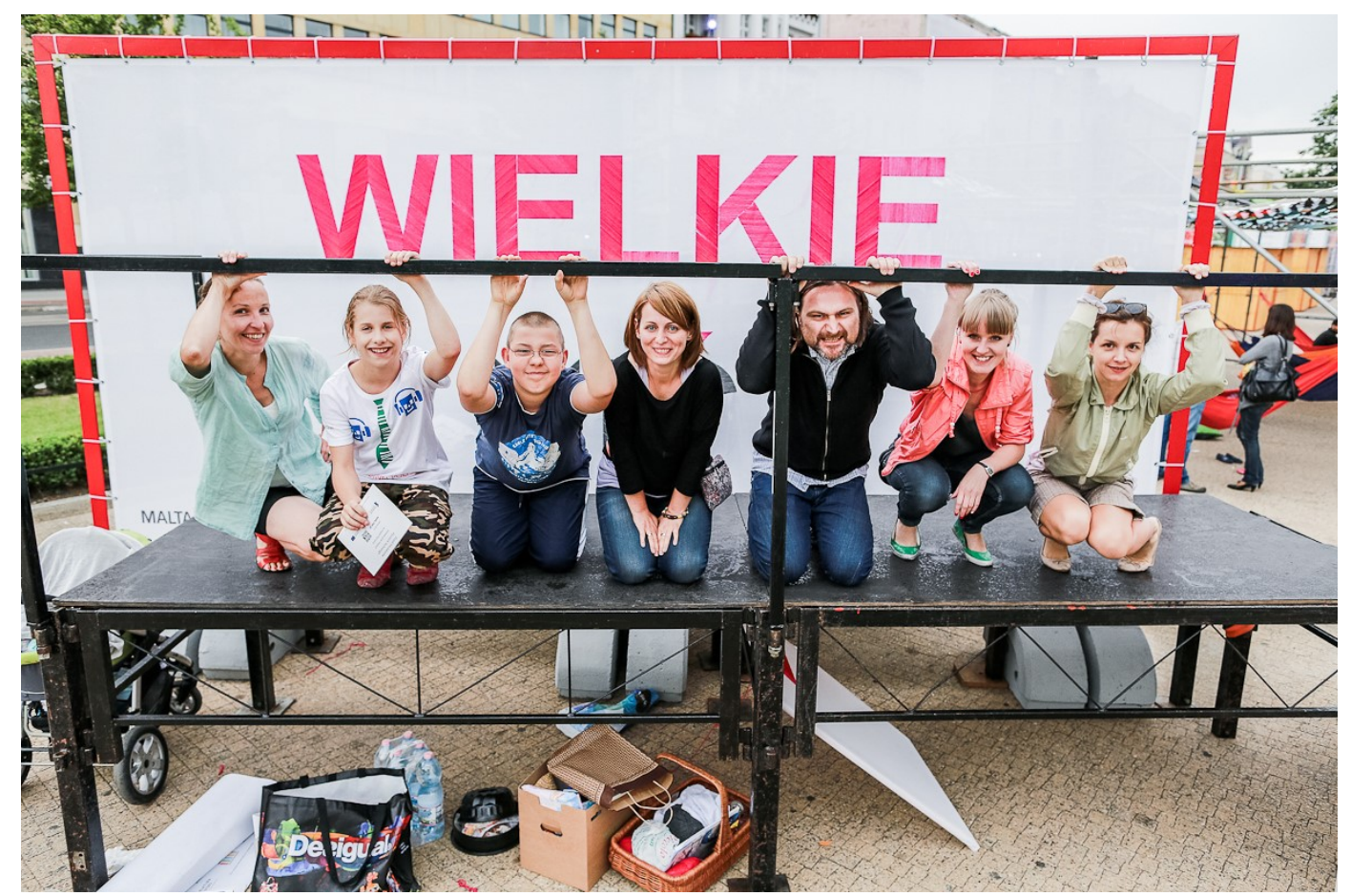

Figure 7. After many hours of embroiding, we are proud and fulfilment. (fot. Marcin Oliva Soto). 


\section{RULES OF PLAY - A CHANGE OF HUMAN CONSCIOUSNESS}

I also would like to point out the physical dimension of this activity. It satisfiesy a human need for doing something by hand. In our era of "the death of the working man" people miss that very strongly. This is why we chose embroidery. What is so special about it? Nothing. In a way, this is a simple activity. The most interesting thing about it, is how we can use an ordinary thing and find the extraordinary within the ordinary. Embroidery is known to almost everybody from their childhood, because many grandmothers still do handiwork of this kind. It used to be a collective work. In our project we are returning to this tradition. Why are we doing this? I believe that the most important thing in forming a person is a change of consciousness. This can happen through education or social activities. These two missions are perfectly connected by our thread. We have connected these two fields with the help of a very traditional handcraft. And yes, we are trying to change human consciousness. We had the strong impression, that during the performances people felt part of something bigger than just themselves. It was a kind of transgression of everything that is known, conventional, predictable, schematic, rational and undisputed. For a very short time, we were in a space which I will call "I do not know". I could see that this state of mind is very refreshing, affirmative, and that it restores our vitality. If all of this builds our humanity, can we say then that we were more human in doing this?

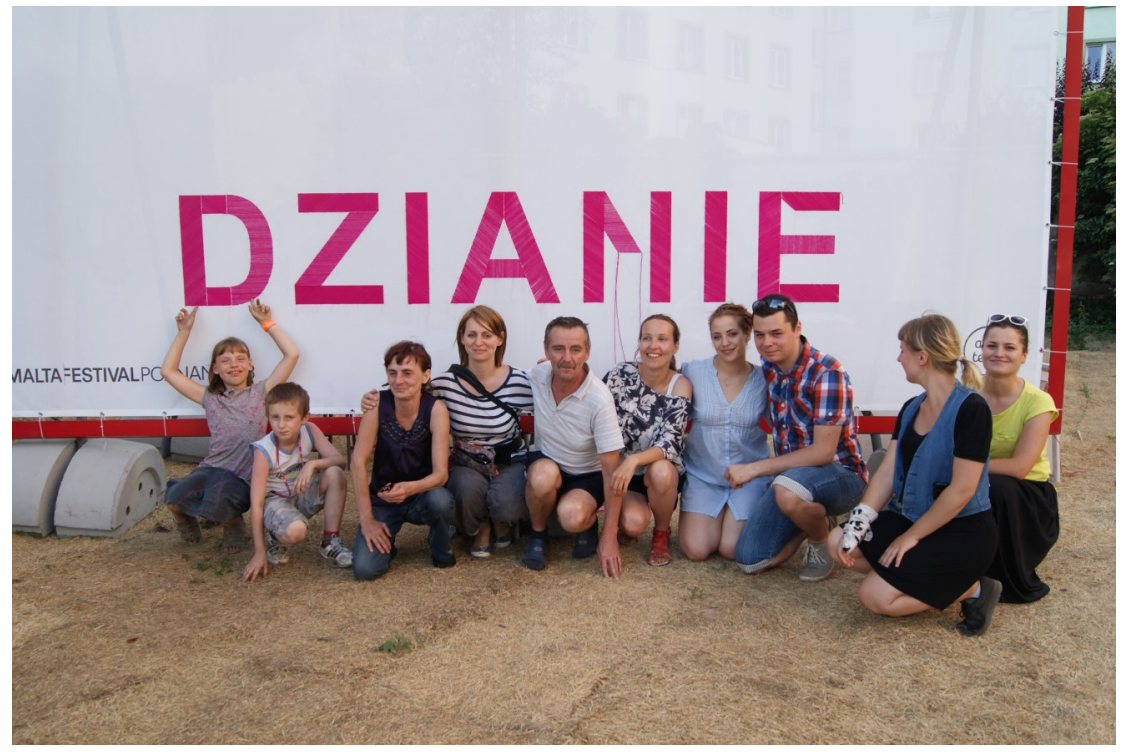

Figure 8. Creating together helps in building a community. (fot. A. Grygiel). 


\section{SYMBOLIC PLAY - CONCLUSION}

Finally, there is a symbolic meaning to our performance. As when a stick becomes a sceptre, or a sieve turns into crown, the thread can become something else. We can see how very small children create and use metaphor without any effort. There is no stick, no sceptre, and no sieve and there is no thread either. It seems that the woollen thread turned into the togetherness. And because of the thread, we can see that we are all connected. And we can together reveal and increase our creativity and power to make changes. Concluding, this is the most important thread of our project - by changing our consciousness we can change our reality.



Figure 9. Project "Wlelkie Nić" connects strangers. (fot. Jacek Zentkowski).

Corresponding author at: Agnieszka Grygiel, Bolesławiec 31, 62-050 Mosina, Poland. E-mail: alateatr@gmail.com 